\title{
ANALYSIS OF POTENTIAL BIOMARKERS OF BRONCHOPULMONARY DYSPLASIA (BPD) IN A NEWBORN RAT VENTILATION MODEL
}

\author{
V. Denervaud ${ }^{1}$, S. Gremlich ${ }^{1}$, J. Schittny ${ }^{2}$, M. Roth-Kleiner ${ }^{1}$ \\ ${ }^{1}$ CHUV, Lausanne, ${ }^{2}$ Institute of Anatomy, Berne, Switzerland
}

Background: BPD is a chronic lung disease affecting preterm infants leading to increased morbidity and mortality. Main risk factors include premature birth, mechanical ventilation (MV), hyperoxia and inflammation. A newborn rat ventilation model with reversible intubation was used to study delayed gene expression modifications to increase our understanding of its pathophysiology.

Methods: LPS was injected intraperitoneally $(2 \mathrm{mg} / \mathrm{kg})$ to male rat pups on postnatal day 4 or 5 to mimic systemic inflammation. Twenty-four hours after injection they were intubated and ventilated for $6 \mathrm{~h}$ with tidal volume of $15 \mathrm{ml} / \mathrm{kg}$ and $21 \%$ or $60 \% \mathrm{O}_{2}$. After weaning from anesthesia, they were returned to their mothers for $48 \mathrm{~h}$. Gene expression was measured by Affymetrix ${ }^{\circledR}$ Gene-Arrays in four groups ( $\mathrm{n}=9 /$ Group) and verified by qPCR.

Results: Expression changes were mainly found in genes involved in inflammation and extracellular matrix remodeling. Among them MMP-9 and several of its regulator genes were significantly modified.

\begin{tabular}{|l|l|l|l|l||}
\hline & Group I: Control & Group II: LPS & $\begin{array}{l}\text { Group III: } \\
\text { LPS+MV+21\%O2 }\end{array}$ & $\begin{array}{l}\text { Group IV: } \\
\text { LPS+MV+60\%O2 }\end{array}$ \\
\hline MMP-9 & 1 & $1.39 \pm 0.22^{*}$ & $1.39 \pm 0.22^{*}$ & $1.64 \pm 0.36^{*}$ \\
\hline CAMP & 1 & $2.22 \pm 0.50^{*}$ & $2.04 \pm 0.46^{*}$ & $2.78 \pm 0.68^{*}$ \\
\hline NGAL & 1 & $1.84 \pm 0.08^{*}$ & $2.14 \pm 0.21^{*}$ & $2.14 \pm 0.20^{*}$ \\
\hline NP4 & 1 & $4.12 \pm 0.19^{*}$ & $3.28 \pm 0.17^{*}$ & $3.29 \pm 0.23^{*}$ \\
\hline
\end{tabular}

[Table 1: qPCR fold changes]

Conclusion: MMP-9 is known to be important in lung development, angiogenesis and tissue repair. In our BPD-model, MMP-9 pathway seemed to be a central target. Several genes increasing MMP-9 activity were synergistically upregulated, highlighting its potential role in lung injury and repair. Therefore, the role of MMP-9 in the pathophysiology of BPD deserves further investigation. 